\title{
The Hidden Cost of COVID-19!
}

The pandemic of COVID-19 has had devastating effects on the lives of people worldwide. Globally, as of December 2020, 220 countries have reported cases of COVID-19, where 69.5 million people have been infected and 1.5 million people have lost their lives. ${ }^{[1]}$ In India, more than 9.8 million people have been infected and more than 142 thousand people have lost their lives. ${ }^{[2]}$ These huge numbers have been overwhelming and have had an impact on patients as well as health-care resources. It has had disastrous effects on people's lives and economies as well. Since there is no cure for COVID-19 yet and considering the time it will take for the vaccine to reach every individual in the world, the number of people affected will only rise. The ultimate burden of this disease which can be foreseen is extremely worrisome. Perhaps, that is why COVID-19 has received undivided attention globally. However, is there any other hidden cost that we are missing?

During the initial stages of the pandemic, many of the hospitals and health-care facilities had to restrict services to the patients. They had to make a drastic change in the way they accommodated patients with all diseases. Only a few hospitals were equipped to test and care for patients with COVID-19. However, as the number of patients grew, the number of beds required along with hospital resources such as the ventilator also grew exponentially. Naturally, this led to a shift in the care of most of the patients who did not have COVID-19. Patients with the least acuity, who had nonemergent conditions including fractures and malignancies and who did not have COVID-19, have been virtually left in the fray. To prevent the spread of infection, these patients have been actively persuaded by the doctors or their relatives not to come to the hospitals or health-care centers, further leading to neglect. Patients themselves have had great reluctance in visiting the hospitals out of fear.

As the country opened up in phases, the non-COVID-19 patients have started visiting the hospitals and other health-care centers. However, there is a serious shortage of doctors and health-care professionals such as nurses and respiratory therapists to care for them. ${ }^{[3,4]}$ Patients who do not have COVID-19 may not get the deserved medical attention and may have health complications due to delays in treatment since a large proportion of the current medical personnel are more focused on managing COVID-19 patients. Perhaps, the only noncommunicable condition that may have decreased during the lockdown period, with less traffic and less people on the roads, is trauma. ${ }^{[5]}$ However, in case of its occurrence, the quality of care they receive would have suffered at every stage, including primary care and transport to a hospital due to nonavailability of ambulances and emergency responders. Availability of beds and acceptability of patients may have been a problem in smaller hospitals. Although emergencies would have received attention, definitive care that they require such as fixation of fractures would have got delayed with its adverse consequences.

Patients of noncommunicable diseases are referred to as "the forgotten patients" by the authors in this article. ${ }^{[6]}$ There has been disruption in health-care delivery, delays in treatment, discontinuation of routine care, loss of human touch, and uncertain physical availability of specialists, in particular. ${ }^{[7]}$ In the process of protecting the non-COVID-19 patients by avoiding exposure to the pathogen in hospitals, more harm may have been caused to them. The toll on non-COVID-19 patients (the unseen numbers) is possibly much higher than on COVID-19 patients.

The management strategies of all conditions have been modified due to the threat of COVID-19, where the choice of treatment is no longer based on a disease outcome, but the one that would maximally reduce the exposure of the patient to COVID-19. Thus, telemedicine for online consultations and medical treatment has been favored the most. ${ }^{[8]}$ Technological advances have enabled visualization of the patient, remote auscultation, and viewing of investigation results including electrocardiograms. Patients and their attendants have been equipped with self-management techniques to self-monitor whenever possible and identification of any potential "red flags" in their disease process.

Chronic respiratory diseases such as chronic obstructive pulmonary disease (COPD), asthma, and cancer have some of the highest morbidity and mortality rates among all diseases. ${ }^{[9]}$ These patients who were otherwise susceptible to respiratory infections suffered due to lack of availability and challenges to care. ${ }^{[10,11]}$ What effect will COVID-19-appropriate behavior have on the other airborne diseases such as tuberculosis is yet to be seen. Cancer care most often involves tumor resection, chemotherapy, and immunosuppression. In view of COVID-19, procedures such as tumor resection were often deferred while the frequency of chemotherapy sessions and degree of immunosuppression was reduced. ${ }^{[12]}$ How this has affected the survival of these patients is yet to be evident.

Patients with acute coronary syndromes are another group of patients that have borne the brunt of the pandemic. A delay in seeking medical help due to hesitation contributes to damage to the myocardium precipitating cardiogenic shock, pulmonary edema, or sudden death. ${ }^{[13]}$ The potential to treat is lost. COVID-19 itself may be associated with coronary thrombosis due to its effect on coagulation, making it further difficult to treat. ${ }^{[13]}$ It is understandable that the treating physician would want to rule out COVID-19 and await test results, but this 
approach takes its toll as well. Patients with severe valvular heart disease anticipating valve replacements and patients with heart failure awaiting ventricular assist devices have had similar problems ${ }^{[12]}$ Similarly, hypertension and diabetes are two noncommunicable diseases that have received much less attention than needed.

The physician monitored care of patients of chronic conditions had to be deferred, while procedures such as joint replacements, corrective surgeries, hernias and hysterectomies also had to be postponed due to COVID-19 pandemic. ${ }^{[14]}$ For these patients, this has translated to prolonged suffering, reduced productivity, and lower quality of life. ${ }^{[14]}$

Even though infertility treatment may have been postponed, pregnancies and deliveries have demanded continued attention being an integral part of nature. Due to a lack of evidence and proper guidelines, two scenarios were seen during the pandemic. With the risk of infection most likely, several hospitals reduced the number of elective surgeries which led to a reduction in access to care, ${ }^{[15,16]}$ while in some other setups, it led to obstetricians favoring cesarean delivery since it is quicker than vaginal delivery. ${ }^{[17]}$ This variation impacted the quality of care for pregnant women.

COVID-19 has had a serious impact on mental health. ${ }^{[18,19]}$ A fear of doom could be seen in the population in the early stages of the pandemic, with people confined to homes during lockdowns. Quarantined individuals have shown several emotional issues such as anxiety, depression, irritability, lack of sleep, and anger ${ }^{[19]}$ With passing time, although many have continued to be careful, in a large proportion of the population, this has changed to defiance. The low mortality rate has instilled a false sense of security among people, especially the younger population. Although partly driven by the need to resume work for economic reasons, many activities happen because of a serious impatience to wait any longer ${ }^{[18]}$ Religious congregations, even though slightly muted, still happen with considerable aplomb. Rules for wearing face masks and social distancing are violated with impunity resulting in "waves" of infection. ${ }^{[20]}$

COVID-19 has not only affected health-care systems but also education and research. ${ }^{[7]}$ Like in other fields, medical and allied health education has been continued online. Although imparting theoretical knowledge has been possible through e-learning, the essential "hands-on" learning of medicine from patients has seriously suffered. ${ }^{[21,22]}$ This raises important questions on the quality of training received by the students in their clinical years of medical education and their level of skill to manage patients. Research has been disrupted first due to the lockdown stay at home order, followed by the risk of infection and financial issues. ${ }^{[23]}$ Clinical trials had to be altered to meet the desired outcomes while there was a lack of patient pool willing to participate in the trials. ${ }^{[23]}$ This affected not only the sample and data but also potentially delayed resultant therapy. On the contrary, research has been conducted on COVID-19 infection and pandemic on a large scale across the world. ${ }^{[23]}$
Overall, the novelty of the COVID-19 disease has undoubtedly had a disastrous effect not only on people who got infected directly but also on the people around them. The mental and physical health of the entire population has been challenged along with overburdened health professionals and health-care systems. Although the vaccine is in near sight, it will be long till every individual is vaccinated and the disease, hopefully eradicated. The deleterious effects of what has been will be everlasting on all aspects of human life. The year 2020 will go down in history as a year unlike any other, with all its implications on every country of the world!

Madhuragauri Shevade ${ }^{1}$, Anitha Nileshwar ${ }^{2}$

${ }^{1} \mathrm{PhD}$ Scholar, Symbiosis Center for Research and Innovation (SCRI), Faculty of Health and Biomedical Sciences, Symbiosis International University, Pune and Associate Vice President Indian Association of Respiratory Care, 2Professor, Department of Anaesthesiology, Kasturba Medical College, Manipal Academy of Higher Education, Manipal, Karnataka State, India

Address for correspondence: Dr. Anitha Nileshwar, Department of Anaesthesiology, Kasturba Medical College, Manipal, Karnataka,

India.

E-mail: anitharshenoy@gmail.com

\section{ReFERENCES}

1. WHO. WHO Coronavirus Disease (COVID-19) Dashboard; 2020. Available from: https://covid19.who.int/. [Last accessed on 2020 Dec 12].

2. GOI. COVID-19 Dashboard; 2020. Available from: https://www.mygov. in/covid-19. [Last accessed on 2020 Dec 12].

3. Wahlster S, Sharma M, Lewis AK, Patel PV, Hartog CS, Jannotta G, et al. The coronavirus disease 2019 pandemic's effect on critical care resources and providers: A Global Survey Chest 2020; E-pub Ahead of print. [Last accessed 2020 Nov 14].

4. Alqahtani JS, Mendes RG, Aldhahir A, Rowley D, AlAhmari MD, Ntoumenopoulos G, et al. Global current practices of ventilatory support management in COVID-19 patients: An international survey. J Multidiscip Healthe 2020;13:1635-48.

5. Waseem S, Nayar SK, Hull P, Carrothers A, Rawal J, Chou D, et al. The global burden of trauma during the COVID-19 pandemic : A scoping review. J Clin Orthop Trauma. Last accessed: $14^{\text {th }}$ November 2020. doi: 10.1016/j.jcot.2020.11.005 [Epub ahead of print].

6. Beck JP. The Forgotten Patients: COVID-19 and the Impact on People Living with Non-communicable Diseases. Health IT News. June $17^{\text {th }}$, 2020. Available from: https://www.healthcareitnews.com/blog/emea/ forgotten-patients-covid-19-and-impact-people-living-non-communica ble-diseases. [Last accessed on 2020 Dec 16].

7. Haleem A, Javaid M, Vaishya R. Effects of COVID-19 pandemic in daily life. Curr Med Res Pract 2020;10:78-9.

8. Das A, Rani P, Vaddavalli P. Tele-consultations and electronic medical records driven remote patient care: Responding to the COVID-19 lockdown in India Anthony. Indian J Ophthalmol 2020;68:1007-12.

9. Salvi S, Kumar AG, Dhaliwal RS, Paulson K, Agrawal A, Koul PA, et al. The burden of chronic respiratory diseases and their heterogeneity across the states of India: The global burden of disease study. Lancet Glob Heal 2018;6:e1363-74.

10. Schultze A, Walker AJ, MacKenna B, Morton CE, Bhaskaran K, Brown JP, et al. Risk of COVID-19-related death among patients with chronic obstructive pulmonary disease or asthma prescribed inhaled corticosteroids: An observational cohort study using the OpenSAFELY platform. Lancet Respir Med 2020;8:1106-20.

11. Elbeddini A, Tayefehchamani Y. Amid COVID-19 pandemic: Challenges with access to care for COPD patients. Res Social Adm Pharm 2021;17:1934-7.

12. Rosenbaum L. Medicine and society the untold toll - The pandemic's effects on patients without COVID-19. N Engl J Med 2020;382:2368-71. 
13. Mafham MM, Spata E, Goldacre R, Gair D, Curnow P, Bray M, et al. COVID-19 pandemic and admission rates for and management of acute coronary syndromes in England. Lancet 2020;396:381-9.

14. Soltany A, Hamouda M, Ghzawi A, Sharaqi A, Negida A, Soliman S, et al. A scoping review of the impact of COVID-19 pandemic on surgical practice. Ann Med Surg 2020;57:24-36.

15. Spurlin E, Han E, Silver E, et al. The Impact of the COVID-19 Pandemic on Obstetric and Gynecologic Procedures and Consults at a Metropolitan Hospital in the Epicenter Journal of Minimally Invasive Gynecology 2020;27:S108-9.

16. Romanis EC, Nelson A. Maternal request caesareans and COVID-19: The virus does not diminish the importance of choice in childbirth. J Med Ethics 2020;46:726-31.

17. Di Toro F, Gjoka M, Di Lorenzo G, De Santo D, De Seta F, Maso G, et al. Impact of COVID-19 on maternal and neonatal outcomes: A systematic review and meta-analysis. Clin Microbiol Infect 2021;27. https://doi.org/10.1016/j.cmi.2020.10.007.

18. Dubey S, Biswas P, Ghosh R, Chatterjee S. Psychosocial impact of COVID-19. Diabetes Metab Syndr Clin Res Rev 2020;14:779-88.

19. Pfefferbaum B, North CS. Mental health and the Covid-19 pandemic. N Engl J Med 2020;383:510-2.

20. Sharma A. Coronavirus in India: Is Public Negligence Causing Surge in Cases? Available from: https://www.dw.com/en/coronavirus-in-india-is -public-negligence-causing-surge-in-cases/a-54394810. [Last accessed on 2020 Dec 16].

21. Alsoufi A, Alsuyihili A, Msherghi A, Elhadi A, Atiyah H, Ashini A, et al. Impact of the COVID-19 pandemic on medical education: Medical students' knowledge, attitudes, and practices regarding electronic learning. PLoS One 2020;15:e0242905.

22. Rajab MH, Gazal AM, Alkattan K. Challenges to online medical education during the COVID-19 pandemic. Cureus 2020;12:e8966.

23. Bian SX, Lin E. Competing with a pandemic: Trends in research design in a time of Covid-19. PLoS One 2020;15:e0238831.

This is an open access journal, and articles are distributed under the terms of the Creative Commons Attribution-NonCommercial-ShareAlike 4.0 License, which allows others to remix tweak, and build upon the work non-commercially, as long as appropriate credit is given and the new creations are licensed under the identical terms.

\begin{tabular}{|l|l|}
\hline \multicolumn{3}{|c|}{ Access this article online } \\
\hline Quick Response Code: & Website: \\
& www.ijrc.in \\
\hline & \\
& \\
\hline
\end{tabular}

How to cite this article: Shevade M, Nileshwar A. The hidden cost of COVID-19! Indian J Respir Care 2021;10:1-3.

Received: $16-12-2020$

Published: 31-01-2021
Accepted: $16-12-2020$ 